\title{
Potential of two-dimensional correlation spectroscopy in analyses of NIR spectra of biological fluids. \\ I. Two-dimensional correlation analysis of protein and fat concentration-dependent spectral variations of milk
}

\author{
Y. Wang ${ }^{1}$, R. Tsenkova ${ }^{2}$, M. Amari ${ }^{3}$, F. Terada ${ }^{3}$, T. Hayashi ${ }^{3}$, A. Abe $^{3}$ and Y. Ozaki ${ }^{1 * *}$ \\ ${ }^{1}$ Department of Chemistry, School of Science, Kwansei-Gakuin University, Uegahara, Nishinomiya 662-8501, Japan \\ ${ }^{2}$ Department of Environment Information and Bio-production Engineering, Faculty of Agriculture, Kobe University, Rokkodai, \\ Nada-ku, Kobe 657, Japan \\ ${ }^{3}$ National Institute of Animal Industry, Tsukuba Norindanchi, PO Box 5, Ibaraki 305, Japan
}

Two-dimensional (2D) correlation analysis has been applied to analyze protein and fat concentration-dependent near-infrared (NIR) spectral variations of milk. Synchronous and asynchronous 2D correlation spectra of milk enhance spectral resolution and provide information about concentration-dependent intensity changes not readily accessible from one-dimensional spectra. The asynchronous 2D correlation map shows marked differences between the protein and fat concentration-dependent spectral changes.

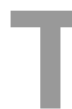
wo-dimensional (2D) correlation spectroscopy has recently received keen interest because it is a totally new and powerful spectral analytical method [1-4]. The 2D correlation spectroscopy enables us to obtain spectral information not readily accessible from one-dimensional spectra by spreading spectral peaks over the second dimension [1-7]. Band assignments and studies of inter- and intramolecular interactions become easier by selective correlations between various bands in synchronous and asynchronous 2D correlation spectra. Probing the specific order of the spectral intensity variations is also possible by inspecting the asynchronous 2D spectra.

Original 2D correlation spectroscopy was proposed by Noda [1,2] in 1986 as 2D correlation mid-infrared (MIR)

* Cor respondence and reprints. 
spectroscopy. In this 2D MIR spectroscopy, a sample system is excited by an external perturbation, which induces a dynamic fluctuation of the vibrational spectrum. A simple cross-correlation analysis was applied to sinusoidally varying dynamic spectral signals to obtain a set of 2D MIR correlation spectra [1,2]. This 2D MIR spectroscopy was successful in the investigations of systems stimulated by a small-amplitude mechanical or electrical perturbation[8,11]. However, the previously developed approach had one shortcoming; the time-dependent behavior (i.e., waveform) of dynamic spectral intensity variations must be a simple sinusoid in order to effectively employ the original data analysis scheme [1,2]. Therefore, in 1993 Noda [3] presented a more generally applicable, yet reasonably simple, mathematical formalism to construct $2 \mathrm{D}$ correlation spectra from any transient or time-resolved spectra having an arbitrary waveform. New 2D correlation spectroscopy was named as generalized 2D correlation spectroscopy $[3,4]$. The newly proposed 2D correlation spectroscopy can be applicable to various types of spectroscopy, including near-infrared (NIR) and Raman spectroscopy. The 2D heterospectral correlation analysis such as 2D NIR-MIR analysis is also possible by use of generalized 2D correlation method.

Since 1993, generalized 2D correlation spectroscopy has been applied to various subjects for basic research [12-21]. For example, temperature-dependent NIR spectral variations of self-associated molecules such as alcohols and amides $[13,16]$, and the secondary structures of proteins $[19,20]$ were investigated by generalized 2D correlation spectroscopy. All the systems investigated thus far were rather simple systems consisting of one to a few components and no one has applied generalized 2D correlation spectroscopy to complicated systems such as biological fluids, tissues, and medical samples.

The purpose of the present paper is to explore potential of two-dimensional correlation spectroscopy in the analyses of NIR spectra of complicated biological fluids. Milk has been taken up as the first example because NIR spectroscopy has recently been used for quantitative analysis and quality evaluation of milk [22,25]. Chemometrics has been employed for the above purposes, but so far there is no report about detailed NIR spectral analysis of milk.

\section{Experimental}

\section{Sample preparation}

Six milk samples from six cows (numbered as cow 402", $\left.406^{\#}, 429^{\#}, 458^{\#}, 926^{\#}, 934^{\#}\right)$ were selected to construct 2D NIR correlation spectra. These cows were under routine feeding management. Table I shows protein and fat contents of the milk samples determined by Milkoscan 134 A/B (N Foss Electric, Denmark).

\section{NIR measurements}

NIR spectra in the $1100-2500 \mathrm{~nm}$ region were measured with a step size of $2 \mathrm{~nm}$ at $40{ }^{\circ} \mathrm{C}$ by an InfraAlyzer $500 \mathrm{NIR}$ spectrometer (Bran-Luebbe). The milk samples were homogenized and incubated into a $40{ }^{\circ} \mathrm{C}$ waterbath prior to NIR measurements. A transflectance liquid sample cell $(0.1 \mathrm{~mm}$ path length) was employed.

\section{Two-dimensional correlation analysis}

A software used in the present study was prepared by one of the authors (Y. Wang) by use of the Array Basic programming language offered by The Galactic Industries Corporation. The algorithm adopted in the 2D software is based upon the newly developed theory of generalized 2D correlation spectroscopy [4]. Two series of 2D NIR correlation spectra have been constructed based upon two series of dynamic spectra consisting of protein and fat concentrationdependent NIR spectra of the milk samples.

\section{Results and discussion}

Figure 1 shows NIR spectra in the $1100-2500 \mathrm{~nm}$ region of milk samples taken from the six cows. The spectra are dominated by two strong absorption bands near 1440 and $1920 \mathrm{~nm}$ due to water, but there also observed several weak features near 1150, 1207, 1722, 1763, 2306, and $2345 \mathrm{~nm}$. Table II summarizes proposed assignments of bands in the NIR spectra of milk. These assignments have been made by referring to NIR spectra of water, proteins, fats, and glucose $[26,27]$.

Figures $2 \mathrm{a}$ and $\mathrm{b}$ shows $2 \mathrm{D}$ NIR correlation spectra in the $1100-1800 \mathrm{~nm}$ region constructed from protein concentration-dependent spectral changes of milk, respectively. In the synchronous spectrum, four autopeaks are observed near $1150,1440,1722$, and $1760 \mathrm{~nm}$, and positive cross peaks are identified between the band at $1440 \mathrm{~nm}$ and the bands at 1210,1722 and $1760 \mathrm{~nm}$ and between the band at $1722 \mathrm{~nm}$ and the bands at 1760 and $1207 \mathrm{~nm}$.

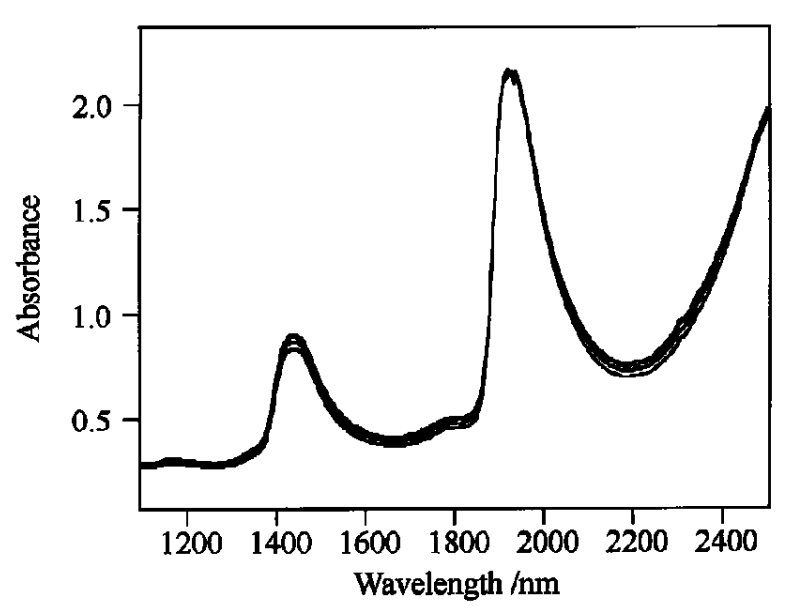

Figure 1. NIR spectra in the $1100-2500 \mathrm{~nm}$ region of six milk samples from six cows.

Table I. Protein and fat contents in milk samples.

\begin{tabular}{lcccccc}
\hline Cow No. & $402^{\#}$ & $406^{\#}$ & $429^{\#}$ & $458^{\#}$ & $926^{\#}$ & $934^{\#}$ \\
\hline Total Protein \% & 3.47 & 3.11 & 3.66 & 3.09 & 2.98 & 3.05 \\
Fat \% & 4.53 & 5.18 & 3.49 & 3.50 & 3.45 & 2.61 \\
\hline
\end{tabular}


Table II. Proposed assignments of bands in the NIR spectra of milk.

\begin{tabular}{|c|c|}
\hline wavelength $(\mathrm{nm})$ & assignments \\
\hline 1150 & $\begin{array}{l}\text { 2nd overtone of } \mathrm{CH}_{2} \text { antisymmetric stret- } \\
\text { ching, } 3 \mathrm{v}_{\mathrm{a}}\left(\mathrm{CH}_{2}\right)\end{array}$ \\
\hline 1207 & $\begin{array}{l}\text { 2nd overtone of } \mathrm{CH}_{2} \text { symmetric stretching, } \\
3 \mathrm{v}_{\mathrm{s}}\left(\mathrm{CH}_{2}\right)\end{array}$ \\
\hline 1440 & $\begin{array}{l}\text { combination of } \mathrm{OH} \text { symmetric and antisym- } \\
\text { metric stretching, } v_{s}(\mathrm{OH})+v_{\mathrm{a}}(\mathrm{OH})\end{array}$ \\
\hline 1722 & $\begin{array}{l}\text { 1st overtone of } \mathrm{CH}_{2} \text { antisymmetric stret- } \\
\text { ching, } 2 \mathrm{v}_{\mathrm{a}}\left(\mathrm{CH}_{2}\right)\end{array}$ \\
\hline 1763 & $\begin{array}{l}\text { 1st overtone of } \mathrm{CH}_{2} \text { symmetric stretching, } \\
2 \mathrm{v}_{\mathrm{s}}\left(\mathrm{CH}_{2}\right)\end{array}$ \\
\hline 1920 & $\begin{array}{l}\text { combination of } \mathrm{OH} \text { antisymmetric stretching } \\
\text { and bending, } v_{\mathrm{a}}(\mathrm{OH})+v(\mathrm{OH})\end{array}$ \\
\hline 2306 & $\begin{array}{l}\text { combination of } \mathrm{CH}_{2} \text { antisymmetric stret- } \\
\text { ching with bending, } v_{\mathrm{a}}\left(\mathrm{CH}_{2}\right)+v\left(\mathrm{CH}_{2}\right)\end{array}$ \\
\hline 2345 & $\begin{array}{l}\text { combination of } \mathrm{CH}_{2} \text { symmetric stretching } \\
\text { with bending, } \mathrm{v}_{\mathrm{s}}\left(\mathrm{CH}_{2}\right)+v\left(\mathrm{CH}_{2}\right)\end{array}$ \\
\hline
\end{tabular}

(a) Synchronous 20 Correlation Map

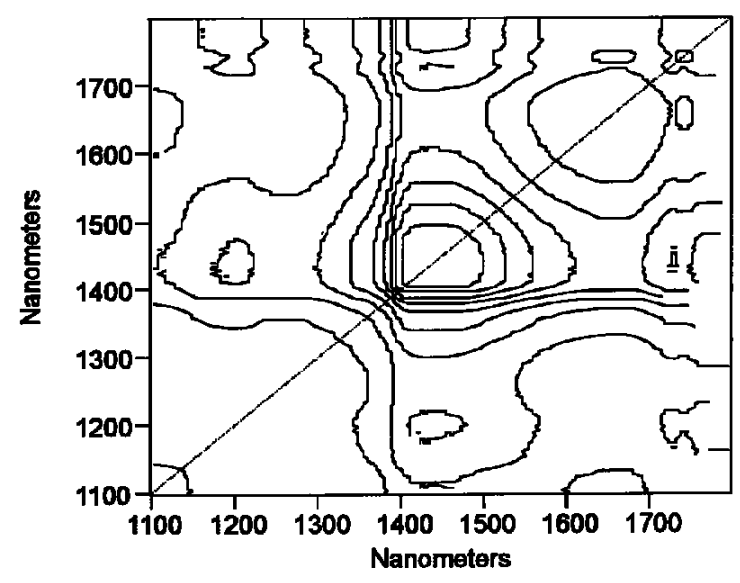

(b) Asymchronous 20 Corrolation Map

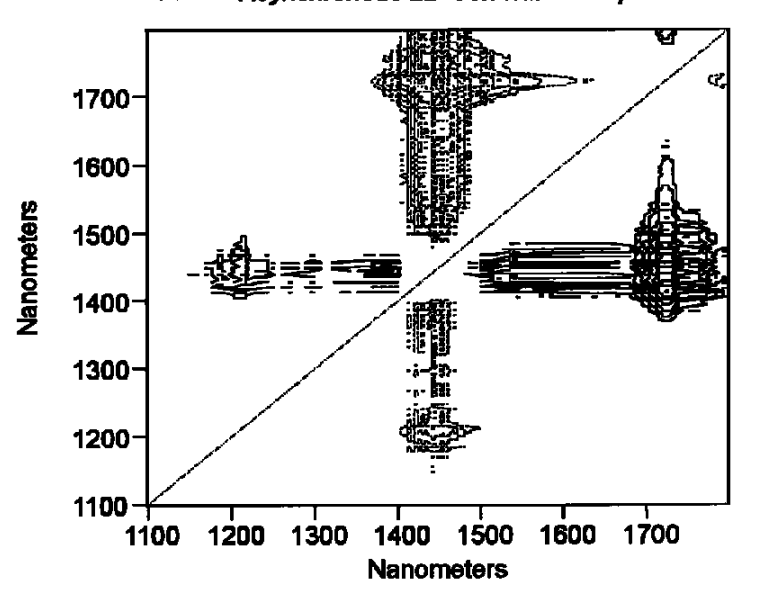

Figure 2. 2D NIR correlation spectra in the $1100-1800 \mathrm{~nm}$ region constructed from protein concentration-dependent spectral changes of milk; (a) synchronous and (b) asynchronous contour maps.
The autopeaks near 1440, 1722, and $1760 \mathrm{~nm}$ correspond to the bands due to the combination of $\mathrm{OH}$ symmetric and antisymmetric stretching modes $\left(\mathrm{v}_{\mathrm{s}}(\mathrm{OH})+\mathrm{v}_{\mathrm{a}}(\mathrm{OH})\right)$ of water and the first overtone of $\mathrm{CH}_{2}$ antisymmetric $\left(2 \mathrm{v}_{\mathrm{a}}\left(\mathrm{CH}_{2}\right)\right)$ and symmetric $\left(2 v_{\mathrm{s}}\left(\mathrm{CH}_{2}\right)\right)$ stretching modes of various components of milk, respectively. The autopeak near $1440 \mathrm{~nm}$ is very broad because the water band near $1440 \mathrm{~nm}$ is composed of contributions from various species of water with hydrogen bonds of different strength. The existence of positive cross peak between 1440 and $1722 \mathrm{~nm}$ and that between 1440 and $1760 \mathrm{~nm}$ shows that the intensity changes in the three bands due to $\left(v_{\mathrm{a}}(\mathrm{OH})+\mathrm{v}_{\mathrm{s}}(\mathrm{OH})\right), 2 \mathrm{v}_{\mathrm{a}}\left(\mathrm{CH}_{2}\right)$, and $2 v_{\mathrm{s}}\left(\mathrm{CH}_{2}\right)$ modes occur similarly in the same direction with the change in the protein concentration.

Of particular note in the asynchronous spectrum is the occurrence of cross peaks between the broad water band near $1440 \mathrm{~nm}$ and the bands at 1722 and $1760 \mathrm{~cm}^{-1}$ due to the first overtone of the $\mathrm{CH}_{2}$ stretching modes. This observation indicates that the intensities of the $v_{s}(\mathrm{OH})+$

(a) Synchronous 2D Correlation Map

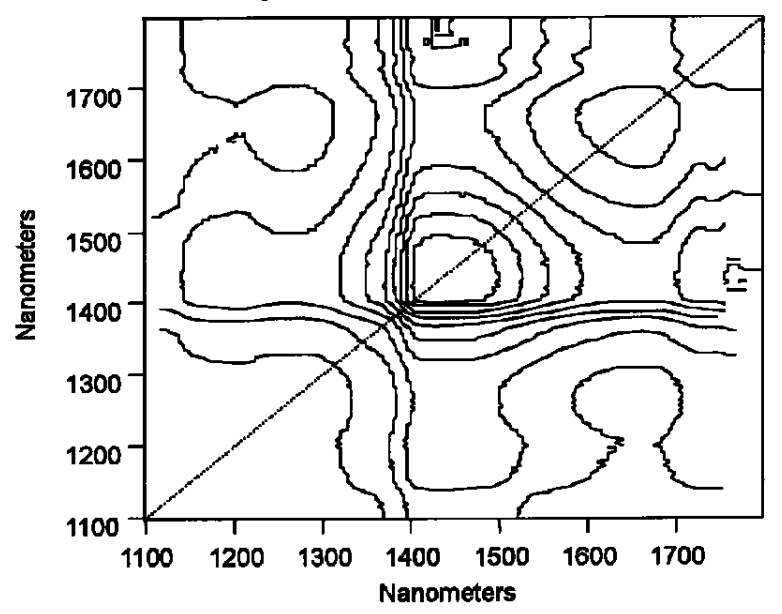

(b) Asynchronous 20 Comelation Map

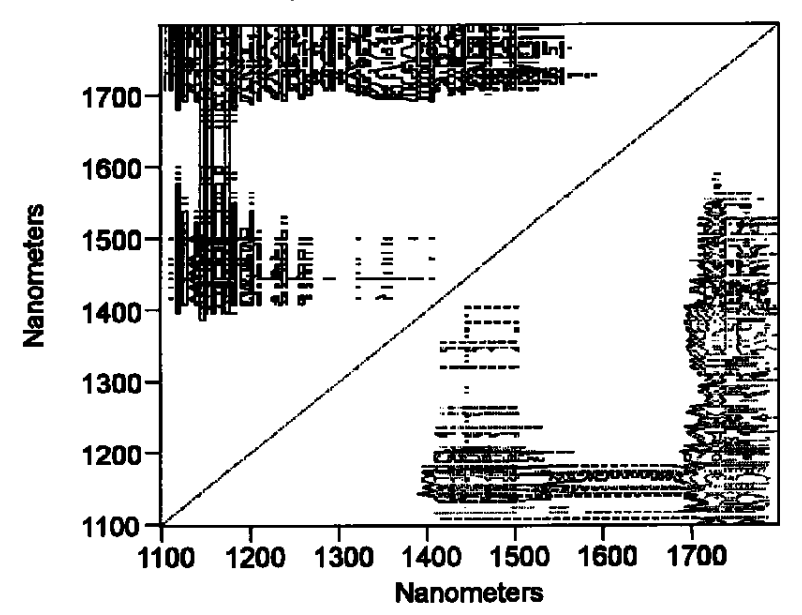

Figure 3. 2D NIR correlation spectra in the $1100-1800 \mathrm{~nm}$ region constructed from fat concentration-dependent spectral changes of milk; (a) synchronous and (b) asynchronous contour maps. 
$v_{\mathrm{a}}(\mathrm{OH})$ band and of the $2 v_{\mathrm{a}}(\mathrm{CH})$ and $2 v_{\mathrm{s}}(\mathrm{CH})$ bands vary out-of-phase each other. This conclusion seems to be inconsistent with that reached from the synchronous spectrum. Probably, the spectral changes in the $1400-1500 \mathrm{~nm}$ and $1710-1770 \mathrm{~nm}$ regions are rather complicated because the water band consists of several component bands and the two $\mathrm{CH}_{2}$ stretching bands contain contributions from various components of milk. We need more thorough studies based upon 2D correlation analysis of each component of milk.

Figures $3 \mathrm{a}$ and $\mathrm{b}$ depicts 2D NIR correlation spectra in the $1100-1800 \mathrm{~nm}$ region constructed from fat concentration-dependent spectral changes of milk, respectively. The synchronous map for fat concentration-dependent spectral variations (Fig. 3a) bears close resemblance to that for protein concentration-dependent spectral variations (Fig. 2a). However, the corresponding asynchronous maps show markedly different correlation patterns. The differences are more clearly observed in the three-dimensional (3D) representation of the asynchronous spectra shown in figures $4 \mathrm{a}$
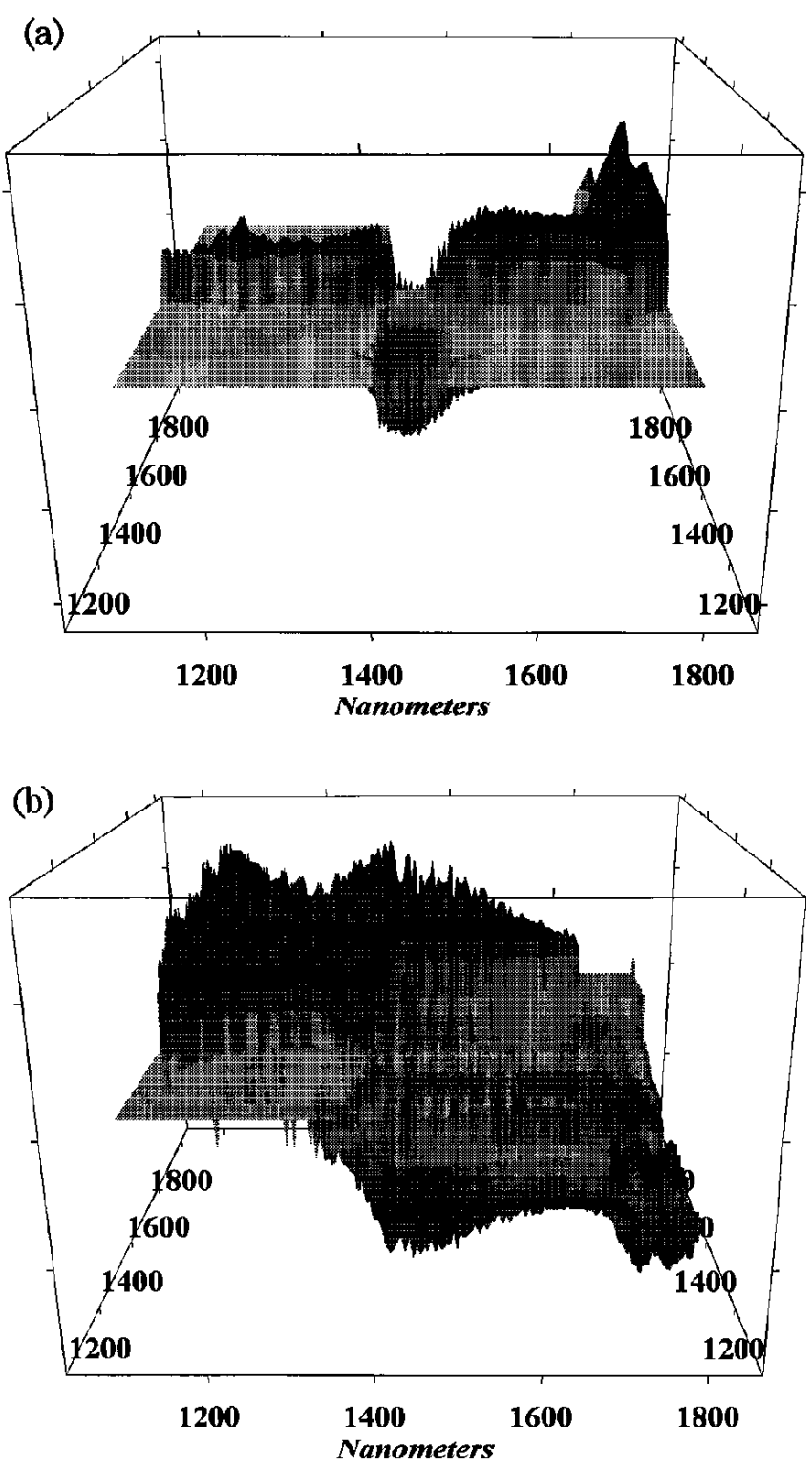

Figure 4. $(a, b)$ Three dimensional (3D) representation of figures $2 b$ and $3 b$, respectively.

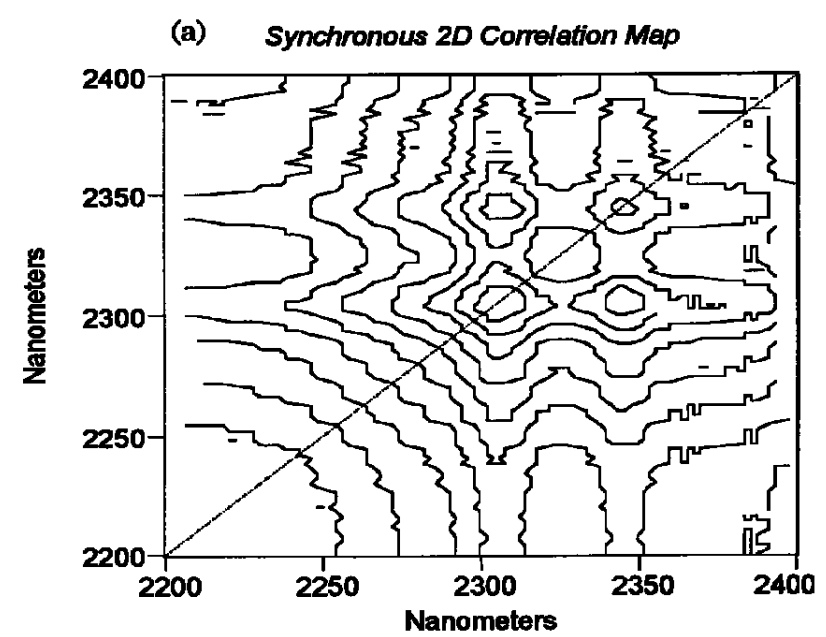

(b) Asynchronous 20 Correlation Map

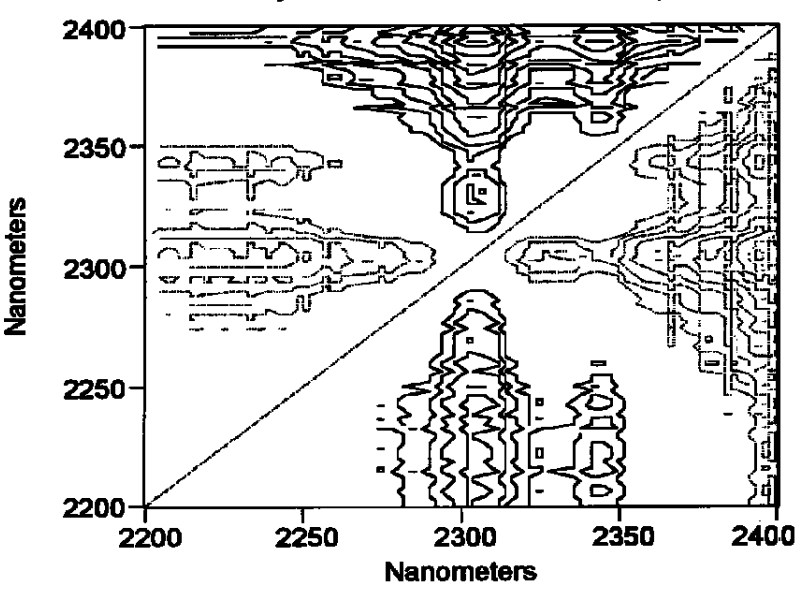

Figure 5. 2D NIR correlation spectra in the $2200-2400 \mathrm{~nm}$ region constructed from protein concentration-dependent spectral changes of milk; (a) synchronous and (b) asynchronous contour maps.

and $b$. It is noted that the most clear differences are concerned with the cross peaks between the band at 1722 or $1760 \mathrm{~nm}$ arising from the $\mathrm{CH}_{2}$ groups and the broad water band near $1440 \mathrm{~nm}$. Therefore, it seems that the spectral changes in the asynchronous maps between the protein and fat concentration-dependent spectra reflect the hydrophilicity and hydrophobicity of the proteins and fat. Of particular interest is that the wavelengths (1722 and $1760 \mathrm{~nm})$, which show the distinct differences in the asynchronous spectra, were used as specific wavelengths in a chemometric model which predicted the concentrations of total proteins and fat [25]. Thus, the 2D correlation analysis may be useful to interpret chemometric models and to predict specific wavelengths.

In figures $5 \mathrm{a}$ and $\mathrm{b}$ are shown synchronous and asynchronous 2D NIR correlation spectra in the $2200-2400 \mathrm{~nm}$ region constructed from protein concentration-dependent spectral changes of milk, respectively. The corre-sponding spectra for fat concentration-dependent spectral changes are presented in figures $6 \mathrm{a}$ and $\mathrm{b}$, respectively. 
(a) Synchronous 2D Correlation Map

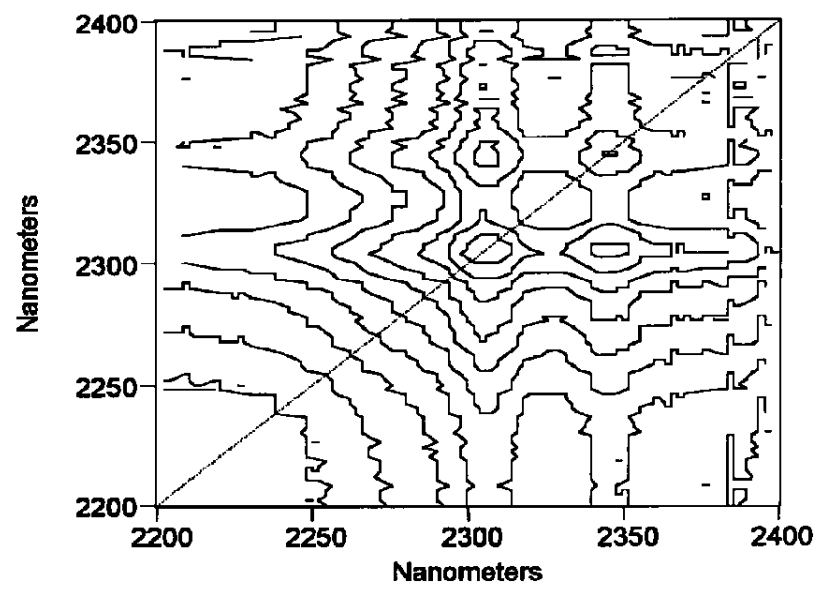

(b) Asynchmonous 2D Correlation Map

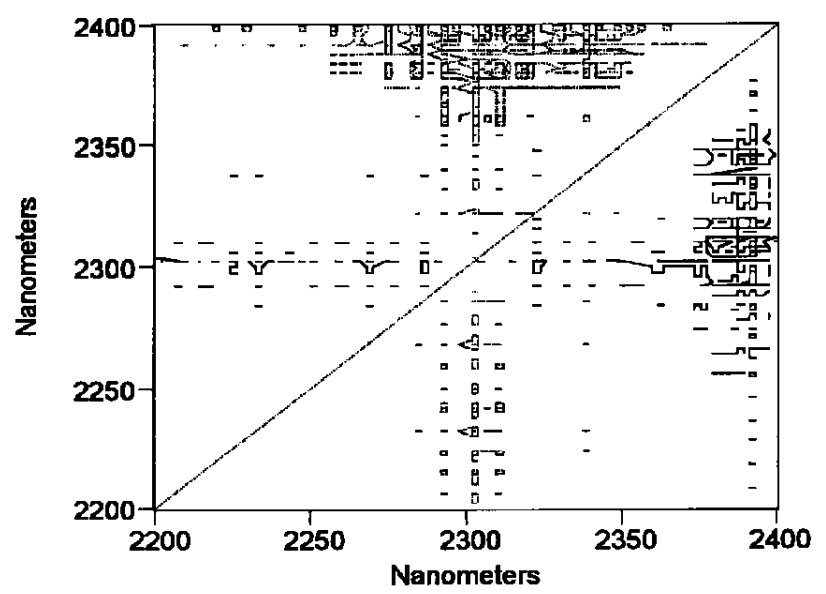

Figure 6. 2D NIR correlation spectra in the $2200-2400 \mathrm{~nm}$ region constructed from fat concentration-dependent spectral changes of milk; (a) synchronous and (b) asynchronous contour maps.

The synchronous spectra are again very similar to each other. Compared with the original spectra shown in figure 1, the synchronous 2D correlation spectra yield rich content of spectral features; spectral enhancement is obtained by the 2D correlation analysis. Two autopeaks are observed at 2306 and $2345 \mathrm{~nm}$. These peaks are probably assignable to combination of $\mathrm{CH}_{2}$ antisymmetric stretching and bending mode and that of $\mathrm{CH}_{2}$ symmetric stretching and bending mode, respectively. Again, the asynchronous maps show marked differences between the protein and fat concentration-dependent intensity changes as is evident from figures $7 \mathrm{a}$ and $\mathrm{b}$. A number of cross peaks are observed at 2325, 2355, 2365, 2380 , and $2390 \mathrm{~nm}$ in the asynchronous map of the protein concentration-dependent intensity variations. Two of them (2355 and $2380 \mathrm{~nm}$ ) are recognized in the second derivative of the spectra in figure 1. Most of the NIR bands above $2300 \mathrm{~nm}$ are assignable to the $\mathrm{CH}_{2}$ combination modes $[26,27]$ so that the cause for the distinct differ-ences in the
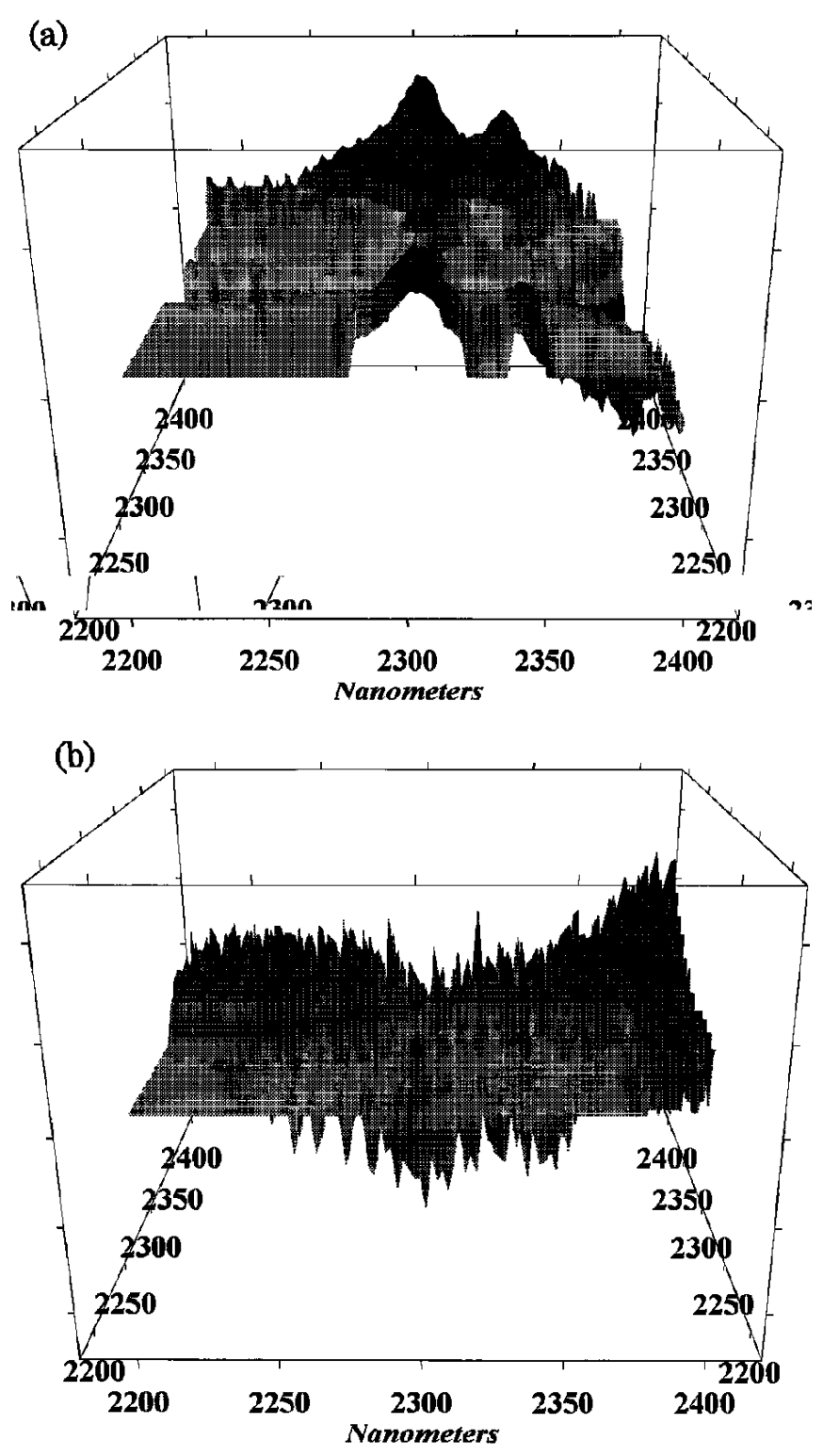

Figure 7. (a,b) Three dimensional (3D) representation of figures $5 \mathrm{~b}$ and $6 \mathrm{~b}$, respectively.

asynchronous spectra in the $2200-2400 \mathrm{~nm}$ region may be the same as that in the $1100-1800 \mathrm{~nm}$ region.

In conclusion, the present study has demonstrated the potential of generalized 2D correlation spectroscopy in the analysis of NIR spectra of milk. The 2D correlation analysis has revealed the existence of a number of buried bands, and in addition it has turned out that it helps explain the reasons why certain wavelengths are selected in a chemometric calibration model. More detailed 2D correlation analyses of milk and blood are now under way in our group and will be reported soon.

\section{Acknowledgements}

This work was supported by the Program for Promotion of Basic Research Activities for Innovative Biosciences (PROBRAIN). 


\section{References}

1. Noda, I. Bull. Am. Phys. Soc. 1986, 31, 520.

2. Noda, I. Appl. Spectrosc. 1990, 44, 550.

3. Noda, I. Appl. Spectrosc. 1993, 47, 1329.

4. Noda, I. Abstract of Papers in 2nd International Symposium on Advanced Infrared Spectroscopy, 1996, Durham NC, USA.

5. Ozaki, Y.; Noda, I. J. Near Infrared Spectrosc. 1996, 4, 85.

6. Ozaki, Y.; Liu, Y.; Noda, I. Appl. Spectrosc. 1997, 51, 526.

7. Ozaki, Y.; Wang, Y. J. Near Infrared Spectrosc., in press.

8. Palmer, R. A.; Manning, C. J.; Chao, J. L.; Noda, I.; Dowrey, A. E.; Marcott, C. Appl. Spectrosc. 1991, 45, 12.

9. Marcott, C.; Noda, I.; Dowrey, A. E. Anal. Chim. Acta 1991, 250, 131.

10. Gregoriou, V. G.; Chao, J. L.; Toriumi, H.; Palmer, R. A. Chem. Phys. Lett. 1991, 179, 491.

11. Noda, I.; Dowrey, A. E.; Marcott, C. 1993, 47, 1317.

12. Roselli, C.; Burie, J. R.; Mattioli, T.; Boussa, A. Biospectrosc. $1995,1,329$.

13. Noda, I.; Liu, Y.; Ozaki, Y.; Czarnecki, M. A. J. Phys. Chem. 1995, 99, 3068.

14. Liu, Y.; Ozaki, Y.; Noda, I. J. Phys. Chem. 1996, 100, 7326.

15. Noda, I.; Liu, Y.; Ozaki, Y. J. Phys. Chem. 1996, 100, 8665.

16. Noda, I.; Ozaki, Y. J. Phys. Chem. 1996, 100, 8674.

17. Gadalleta, S. J.; Gericke, A.; Boskey, A. L.; Mendelsohn, R. Biospectrosc. 1996, 2, 353.
18. Ozaki, Y.; Liu, Y.; Noda, I. Macromolecules 1997, 30, 2391.

19. Nabet, A.; Pezolet, M. Appl. Spectrosc. 1997, 51, 466.

20. Sefara, N. L.; Magtoto, N. P.; Richardson, H. H. Appl. Spectrosc. 1997, 51, 536.

21. Czarnecki, M. A.; Wu, P.; Siesler, H. W. Chem. Phys. Lett., in press.

22. Sato, T.; Yoshino, M.; Furukawa, S.; Someya, Y.; Yano, N.; Uozumi, J.; Iwamoto, M. J. Zootech. Sci. 1987, 58, 698.

23. Kamishikiryo-Yamashita, H.; Oritani, Y.; Takamura, H.; Matoba, T. J. Food Sci. 1994, 59, 313

24. Tsenkova, R. N.; Yordanov, K. I.; Itoh, K.; Shide, Y.; Nishibu, Y. Proc. Third International Dairy Housing Conference, Orlando, 1994; p 82.

25. Purnomoadi, A.; Batajoo, K. K.; Higuchi, K.; Amari, M.; Ueda, K.; Nishida, T.; Kurihara, M.; Terada, F., submitted for publication.

26. Murry, I.; Williams, P. C. in: Near Infrared Technology in Agricultural and Food Industries, Williams, P. C. and Norris, K. H. Eds., American Association of Cereal Chemists, Inc. St. Paul, Minnesota, 1990; p 17.

27. Obsorne, B. G.; Fearn, T.; Hindle, P. H. Practical NIR Spectroscopy with the applications in Food and Beverage Analysis, $2^{\text {nd }}$ Ed. Longman Scientific \& Technical, London, 1993.

28. Maeda, H.; Ozaki, Y.; Tanaka, M.; Hayashi, H.; Kojima, T. J. Infrared Spectrosc. 1995, 3, 191. 